ONLINE MUTATION REPORT

\title{
Molecular analysis of the aldolase B gene in patients with hereditary fructose intolerance from Spain
}

\author{
J C Sánchez-Gutiérrez, T Benlloch, M A Leal, B Samper, I García-Ripoll, J E Felíu
}

J Med Genet 2002;39:e56 (http://www.jmedgenet.com/cgi/content/full/39/9/e56)

$\mathrm{H}$ ereditary fructose intolerance (HFI) is an autosomal recessive metabolic disorder caused by aldolase (fructosediphosphate aldolase, EC 4.1.2.13) B deficiency. ${ }^{1}$ The $\mathrm{B}$ isoform of aldolase is critical for the metabolism of exogenous fructose by the liver, kidney, and intestine, since it can use fructose-1-phosphate as substrate at physiological concentrations, unlike aldolases A and C. Affected subjects suffer abdominal pain, vomiting, and hypoglycaemia after the ingestion of fructose, sucrose, or sorbitol. Continued ingestion of noxious sugars causes hepatic and renal injury, which eventually leads to liver cirrhosis and sometimes death, particularly in small infants. ${ }^{1}$ Treatment consists of strict elimination of fructose, sucrose, and sorbitol from the diet immediately after HFI is suspected. This diet exclusion therapy allows for a rapid recovery and, if liver and kidney damage is not irreversible, an uneventful course thereafter. Confirmatory diagnosis is generally made by intravenous fructose tolerance tests and assays of aldolase B activity in hepatic biopsies.

Since the gene coding for human aldolase B $(A L D O B)$ was cloned, ${ }^{2}$ at least 22 different mutations associated with HFI have been described. ${ }^{3}{ }^{4}$ Kinetic analyses of recombinant aldolase B mutants and molecular modelling studies have shown important structure-function implications for several aldolase $B$ residues affected by HFI mutations..$^{5-8}$ The first HFI mutation identified, termed Al49P, ${ }^{9}$ is a $\mathrm{G} \rightarrow \mathrm{C}$ transversion at the first base of codon 149, which replaces the normal alanine by a proline residue. This missense mutation accounts for more than $50 \%$ of mutant alleles in HFI patients from different populations world wide ${ }^{3}$; the frequency of heterozygous carriers in the United Kingdom has been estimated to be $1.32 \pm$ $0.49 \%$, which allows the prediction of an incidence of HFI associated with the Al49P allele of 1 in 23000 births. ${ }^{10}$ The three more common aldolase B mutations, Al49P, Al74D, and N334K, account for more than $80 \%$ of HFI alleles in populations from European countries. ${ }^{41}$ Although there are many reports dealing with the identification of aldolase B mutations associated with HFI in different European populations, studies on the incidence of these mutations in Spanish subjects have not been reported.

In this work, we have analysed the molecular defects in the $A L D O B$ gene in 28 HFI patients from Spain. For this purpose, we have performed PCR amplification of the aldolase B coding exons from the probands and subsequent analysis by restriction endonuclease digestion, allele specific oligonucleotide (ASO) hybridisation, and direct sequencing. Our results have allowed us to estimate the frequencies of HFI alleles in Spanish patients, as well as to discover two novel mutations in the $A L D O B$ gene (g.4271C $>\mathrm{G}$ and g.1133G $>\mathrm{A}$ ) that can cause HFI.

\section{MATERIALS AND METHODS}

\section{Subjects}

Twenty-eight HFI patients from 21 independent families, referred by hospitals in Spain, were studied. Probands were resident in the following regions: Madrid ( 11 families), Andalusia (4), Galicia (3), Estremadura (1), Valencia (1), and Spanish possessions in North Africa (1). HFI diagnosis was based on enzymatic studies (deficient aldolase B activity in hepatic biopsies from 16 patients) or clinical symptoms (six patients). Another six subjects were suspected to suffer from HFI on the basis of dietary intolerance with episodes suggestive of hypoglycaemia and occurrence of the disease in their first degree relatives.

\section{Reagents}

Thermostable DNA polymerase, deoxynucleotides, and general PCR products were from Biotools (Madrid, Spain). Agarose and acrylamide were purchased from Bio-Rad (Madrid, Spain). Restriction enzymes and DNA sequencing kits were from New England Biolabs (Hitchin, UK) and Promega (Mannheim, Germany). $\left[\alpha-{ }^{32} \mathrm{P}\right] \mathrm{dCTP}$ and $\left[\gamma_{-}{ }^{32} \mathrm{P}\right] \mathrm{ATP}$ were obtained from American Radiolabeled Chemicals (St Louis,

\section{Key points}

- Hereditary fructose intolerance (HFI) is an autosomal recessive metabolic disease caused by aldolase $B$ deficiency. The incidence of mutations in the aldolase $B$ gene $(A L D O B)$ associated with HFI in Spanish subjects has not been studied previously.

- The objective of the study was to identify the mutations present in the ALDOB gene in HFI patients from Spain.

- We applied a combination of PCR amplification, restriction enzyme digestion, allele specific oligonucleotide hybridisation, and direct sequencing to analyse genomic DNA and cDNA isolated from blood or liver biopsies from 28 Spanish HFI patients (21 families).

- Six different mutations in the ALDOB gene were found in Spanish HFI patients. Four of these mutations, A149P, A174D, $44 \mathrm{E} 4$, and N334K, have been previously described. The other two are novel mutations; one is a $C \rightarrow G$ transversion in exon 6 (g.427l $>\mathrm{G})$, which is deduced to replace a proline with an arginine residue at position 184 in the aldolase B protein (suggested trivial name P184R). The other novel mutation is a $G \rightarrow A$ transition in the last nucleotide of exon 3 (g.1133G>A), which appears to cause a deletion of 12 nucleotides from aldolase $B$ mRNA by altering pre-mRNA splicing and a reduction of $m R N A$ accumulation in liver, as suggested by aldolase B cDNA analysis. This latter mutation is deduced to eliminate residues 104-107 from the aldolase B protein (suggested trivial name V104_K107del).

- These findings unveil the frequencies of HFI alleles in Spanish patients and provide the basis for genetic diagnosis of the disease in Spain. 
Table 1 Oligonucleotides used as primers for amplification of aldolase $B$ exons

\begin{tabular}{|c|c|c|c|}
\hline Exon & Primer & Sequence $\left(5^{\prime}-3^{\prime}\right)$ & $\begin{array}{l}\text { Fragment size } \\
\text { (bp) }\end{array}$ \\
\hline 2 & $\begin{array}{l}\text { E2+ } \\
\text { E2- }\end{array}$ & $\begin{array}{l}\text { GTCATGCATCCATCTGAG } \\
\text { GTCTACTGAGTCTTCTGC }\end{array}$ & 319 \\
\hline 3 & $\begin{array}{l}\text { E3+ } \\
\text { E3- }\end{array}$ & $\begin{array}{l}\text { GAGATGATGTGGAGAAGG } \\
\text { ATGTTCAGAGTGTGGCC }\end{array}$ & 373 \\
\hline 4 & $\begin{array}{l}\text { E4+ } \\
\text { E4- }\end{array}$ & $\begin{array}{l}\text { GTCCCTCGCACTAATACA } \\
\text { CCTTGTTCCTTCTTAC }\end{array}$ & 258 \\
\hline 5 & $\begin{array}{l}\text { E5+ } \\
\text { E5- }\end{array}$ & $\begin{array}{l}\text { CTTGATGGCCTCTCAGAG } \\
\text { GCTCTGAAGAAAACTCTAG }\end{array}$ & 214 \\
\hline 5 & $\begin{array}{l}\mathrm{E} 5+\mathrm{B} \\
\mathrm{E} 5-\end{array}$ & $\begin{array}{l}\text { CTCAAGCACAGTGGATTG } \\
\text { GCTCTGAAGAAAACTCTAG }\end{array}$ & 339 \\
\hline 6 & $\begin{array}{l}\text { E6+ } \\
\text { E6- }\end{array}$ & $\begin{array}{l}\text { GCAACTGAAGAATCTCCT } \\
\text { AGTAACAGCTGTTACCTA }\end{array}$ & 230 \\
\hline 7 & $\begin{array}{l}\text { E7+ } \\
\text { E7- }\end{array}$ & $\begin{array}{l}\text { GTCAAGTGGCTCTATGAC } \\
\text { CTTGTGGCTCTCCAAAGA }\end{array}$ & 294 \\
\hline 8 & $\begin{array}{l}\text { E8+ } \\
\text { E8- }\end{array}$ & $\begin{array}{l}\text { GCAGGGTATATAAGGTGG } \\
\text { GTAGATAAGAGGTGGCAG }\end{array}$ & 279 \\
\hline 9 & $\begin{array}{l}\text { A9+ } \\
\text { A9- }\end{array}$ & $\begin{array}{l}\text { TGGTATCCCCAGCAATATTCAG } \\
\text { ACTAGAAGCACTGGAGCTAGGCT }\end{array}$ & 299 \\
\hline 9 & $\begin{array}{l}\text { E9+ } \\
\text { E9- }\end{array}$ & $\begin{array}{l}\text { CATGAGAGGCAGACAGGGT } \\
\text { GCAAGGAAACTGCTGTGTG }\end{array}$ & 390 \\
\hline
\end{tabular}

For each of exons 5 and 9 , two PCR fragments of different sizes were amplified, the longer ones being used for sequencing purposes.

MO, USA), and $\left[\alpha-{ }^{35} S\right] d A T P$ was from Nuclear Iberica (Madrid, Spain). Reagents for reverse transcription were purchased from Applied Biosystems (Madrid, Spain). The remaining reagents were from Roche (Barcelona, Spain), Sigma (Madrid, Spain), or Merck (Barcelona, Spain).

\section{Genomic DNA analysis}

Genomic DNA was prepared from peripheral blood samples (1-2 ml) or from hepatic biopsies (about $10 \mathrm{mg}$ ) by standard procedures. $^{12}{ }^{13}$ Several fragments comprising the coding exons of the human $A L D O B$ gene plus exon-intron boundaries were amplified by PCR in a Perkin Elmer GeneAmp PCR System 2400 apparatus, in a reaction mixture composed of standard PCR buffer, $2 \mathrm{mmol} / \mathrm{l} \mathrm{MgCl}$, 200 pmol/l each dNTP, 0.3-0.6 $\mu \mathrm{mol} / \mathrm{l}$ each primer, 1.25 units thermostable DNA polymerase, and $500 \mathrm{ng}$ of genomic DNA, in a final volume of $50 \mu \mathrm{l}$. Forty PCR cycles were performed under the following reaction conditions: denaturation at $94^{\circ} \mathrm{C}$ for 45 seconds, annealing at $55-61^{\circ} \mathrm{C}$ for 45 seconds, and extension at $72^{\circ} \mathrm{C}$ for 45 seconds. A final elongation was carried out at $72^{\circ} \mathrm{C}$ for five minutes. The primers used, derived from the genomic sequence of human $A L D O B$ gene, ${ }^{2}$ are shown in table 1. All PCR products and endonuclease digestion products were resolved by electrophoresis on agarose gels, stained with ethidium bromide, and photographed under UV light. In all the electrophoretic gels, a 1 kb DNA ladder (Invitrogen, Barcelona, Spain) was run as a DNA size marker.

To investigate the presence of the prevalent mutation, Al49P, a 214 bp DNA fragment was PCR amplified from genomic DNA using oligonucleotides E5 + and E5- as primers, and subjected to digestion with the restriction endonuclease $B s a \mathrm{HI}$. This enzyme is an isoschizomer of AhaII, which cleaves the PCR products at the site of the Al49P mutation. ${ }^{9}$ Mutant DNA fragments were excised into two digestion products of 151 and $63 \mathrm{bp}$, while the wild type ones were resistant to endonuclease digestion.
The presence of the A174D mutation was analysed by allele specific oligonucleotide (ASO) hybridisation of DNA fragments corresponding to exon 5 amplified by PCR as above. ${ }^{14}$ For this purpose, about $200 \mathrm{ng}$ of PCR products were denatured and immobilised on nylon membranes by dot blotting, with the aid of a Bio-dot apparatus (Bio-Rad). Exon 5 fragments subcloned in pBluescript containing the wild type or the A174D sequences were also PCR amplified and processed as above, and served as positive controls. Membranes were prehybridised in a solution containing $6 \times$ SSC $(0.09 \mathrm{~mol} / \mathrm{l}$ sodium citrate and $0.9 \mathrm{~mol} / \mathrm{l} \mathrm{Na} \mathrm{Cl}), 5 \times$ Denhardt's (0.1\% Ficoll, $0.1 \%$ polyvinylpyrrolidone, and $0.1 \%$ bovine serum albumin), and $100 \mu \mathrm{g} / \mathrm{ml}$ denatured salmon sperm DNA for two hours at $65^{\circ} \mathrm{C}$. They were then hybridised overnight at $37^{\circ} \mathrm{C}$ by the addition of $100 \mathrm{ng}$ of allele specific oligonucleotide probes, previously labelled at their $5^{\prime}$ ends

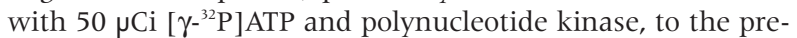
hybridisation solution. The sequences of the probes used were: wild type, 5'- TCGCTACGCCAGCATCT-3'; A174D, 5'AGATGCTGTCGTAGCGA-3'. Blots were washed three times in $6 \times$ SSC, $0.1 \%$ sodium dodecyl sulphate for 10 minutes at room temperature, and then twice in $6 \times$ SSC, $0.01 \%$ sodium dodecylsulphate at $54^{\circ} \mathrm{C}$ for two minutes (high stringency wash). Blots were then exposed to $x$ ray films for autoradiography.

The presence of the $\Delta 4 \mathrm{E} 4$ mutation was identified by ASO hybridisation of exon 4 fragments, ${ }^{15}$ PCR amplified from genomic DNA with oligonucleotides E4+ and E4- as primers. Conditions for sample transfer to nylon membranes, prehybridisation, hybridisation, oligonucleotide labelling, and membrane washes were as described above for the detection of the A174D mutation, with the exception that the high stringency wash was made in $6 \times \mathrm{SSC}, 0.1 \%$ sodium dodecylsulphate for two minutes at $63^{\circ} \mathrm{C} . .^{15}$ Oligonucleotide probes were: wild type, 5'-GCAGGAACAAACAAAGAAAC-3'; $\triangle 4 \mathrm{E} 4$, 5'-GCAGGAACAAAGAAACCACC-3'.

The presence of the N334K mutation was analysed by amplification of a 299 bp DNA fragment by PCR, using oligonucleotides A9+ and A9- as primers, and digestion with the restriction endonuclease $D d e$ I. Wild type DNA fragments were excised into two digestion products of 241 and $58 \mathrm{bp}$. The mutation introduces an additional $D d e$ I target at the site of the mutation (CTAAG), so that digestion of the mutant fragments is expected to render three products of 141, 100, and $58 \mathrm{bp}$.

To confirm the occurrence of the mutations detected by the methods described above, as well as to carry out a screening for additional mutant aldolase $\mathrm{B}$ alleles, direct sequence determination of PCR products corresponding to exons 2-9 was performed, by the chain terminators method (fmol kit, Promega), following the instructions of the manufacturer. The g.4271C $>$ G mutation was further assessed by PCR amplification of a $230 \mathrm{bp}$ fragment enclosing exon 6, which was subjected to digestion with the restriction endonuclease BanI. The mutation destroys a target site for this enzyme (GGTACC); BanI digestion of wild type PCR products is expected to render two fragments of 142 and $88 \mathrm{bp}$, while the mutant ones should not be excised by the endonuclease.

In most cases ( 14 of 21 families), availability of blood samples from patients' relatives allowed us to follow the segregation of the aldolase B alleles. Southern blot analysis was also performed in genomic DNA samples from four probands who appeared to be homozygous for a mutant aldolase B allele and whose parents' samples were not available. For this purpose, genomic DNA was digested with EcoRI, electrophoresed on a $0.8 \%$ agarose gel, and blotted onto nylon membranes by standard laboratory techniques. ${ }^{12}$ The nylon membranes were hybridised with a human aldolase B cDNA probe (nucleotides -37 to 1173 ) previously labelled by random priming with $\left[\alpha-{ }^{32} \mathrm{P}\right] \mathrm{dCTP}$ and then exposed to $x$ ray films for autoradiography. 
A T-1
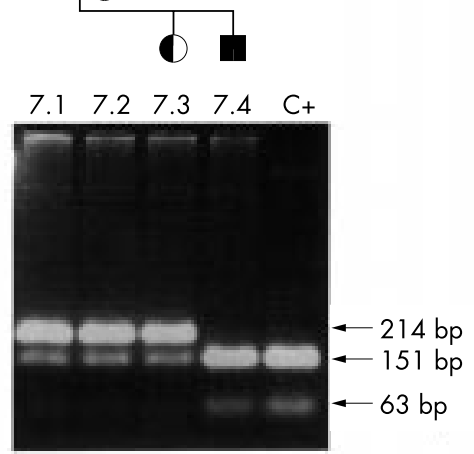

C

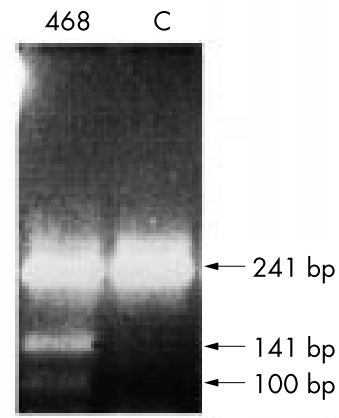

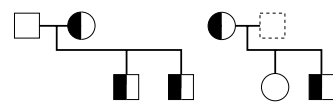

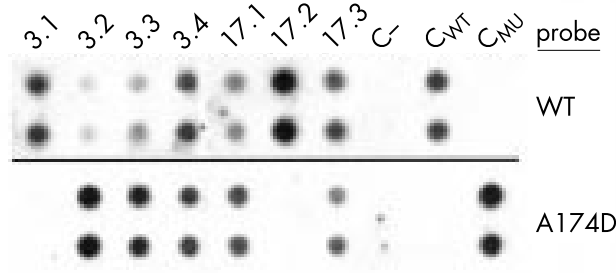

A174D

Figure 1 Detection of common mutations in the ALDOB gene. Several DNA fragments corresponding to the coding exons of the ALDOB gene were amplified by PCR. Then, PCR products were subjected to restriction endonuclease digestion or ASO hybridisation as described. (A) Detection of the A149P mutation in family F7 by endonuclease digestion. Arrows indicate the positions of diagnostic bands of 214, 151, and 63 bp after agarose gel electrophoresis. F7.1, F7.2, and F7.3 are A149P heterozygotes and F7.4 an A149P homozygote. C+, positive control. (B) Detection of the A174D mutation in families F3 and F17 by ASO hybridisation. WT, A174D, membranes hybridised with the wild type or the mutant oligonucleotide, respectively. F3.1 and F17.2 are wild type homozygotes; F3.2, F3.3, F3.4, F17.1, and F17.3, A174D heterozygotes. The dashed symbol represents a subject who was not tested. $C_{-}$, negative control. $C_{W T}, C_{w w}$, positive controls for the wild type and A 174D alleles, respectively. (C) Detection of the N334K mutation in patient 468 by endonuclease digestion. Arrows indicate the positions of diagnostic bands of 241, 141, and 100 bp after agarose gel electrophoresis. An additional expected band of 58 bp is not evident in this picture. 468, N334K heterozygous patient; C, unaffected control. (D) Detection of the $\triangle 4 \mathrm{E} 4$ mutation in families F1 and F5 by ASO hybridisation. WT, $\triangle 4 E 4$, membranes hybridised with the wild type or the mutant oligonucleotide, respectively. F1.1 is a wild type homozygote; F1.2, F1.3, F1.4, F5.1, and F5.2, $44 \mathrm{E} 4$ heterozygotes; F5.3, $\Delta 4 \mathrm{E} 4$ homozygote.

\section{cDNA analysis}

Total RNA was obtained from hepatic biopsy samples by the single step method. ${ }^{16}$ This RNA was used as template to prepare total liver cDNA by reverse transcription in the presence of random hexanucleotides as primers (GeneAmp Gold RNA PCR kit, Applied Biosystems), following the instructions of the manufacturer.

Several DNA fragments corresponding to the sequence of the human aldolase B cDNA were amplified by PCR from total liver cDNA. Thirty PCR cycles were performed at the following reaction conditions: denaturation at $94^{\circ} \mathrm{C}$ for 45 seconds, annealing at $58^{\circ} \mathrm{C}$ for 45 seconds, and extension at $72^{\circ} \mathrm{C}$ for 45 seconds. A final elongation was carried out at $72^{\circ} \mathrm{C}$ for five minutes. DNA fragments comprising nucleotides -82 to 1214 of human aldolase $\mathrm{B} \mathrm{CDNA}^{17}$ were amplified using the following primers: forward, 5'-ATCTGTCTTATTTGGCAGCTG-3' and reverse, 5'-GTGTTGTATTTCCAGCAGTTC-3'. Segments corresponding to nucleotides -37 to 1173 of aldolase B cDNA were subcloned into the EcoRV and EcoRI sites of pBluescript II (Stratagene) by standard laboratory techniques. ${ }^{12}$ The resulting plasmid constructs were sequenced. In another series of experiments, DNA fragments corresponding to positions 250 to 553 of aldolase B CDNA were amplified by PCR from total liver CDNA, using the following primers: forward, 5'CTCTACCAGAAGGACAGC-3' and reverse, 5'GTACCAGTCCATTCTGCT-3'. PCR products were resolved by electrophoresis on $6 \%$ polyacrylamide gels and visualised by ethidium bromide staining. Some PCR reactions were carried out in the presence of $10 \mu \mathrm{Ci}\left[\alpha-{ }^{32} \mathrm{P}\right] \mathrm{dCTP}$ and the products were resolved by polyacrylamide gel electrophoresis and visualised by autoradiography. Radioactivity incorporated into the PCR products was quantitated with an InstantImager apparatus (Packard BioScience Company, Meriden, CT, USA).

\section{Biochemical assays}

Aldolase activity in hepatic biopsies was assayed as described by Blostein and Rutter, ${ }^{18}$ using $10 \mathrm{mmol} / \mathrm{l}$ fructose- 1 phosphate or $2.5 \mathrm{mmol} / \mathrm{l}$ fructose-1,6-bisphosphate as substrates. Liver samples from unaffected subjects served as controls. One enzymatic unit (U) is the amount of enzyme that catalyses the conversion of $1 \mu \mathrm{mol}$ substrate per minute.

Protein was measured by the method of Lowry et a l $^{19}$ using bovine serum albumin as standard.

\section{Statistical analysis}

The $95 \%$ confidence limits for allele frequencies in the population sample were derived from values obtained assuming a binomial distribution. The parameter " $\mathrm{p}$ " was estimated as the sum of frequencies of A149P, $\Delta 4 \mathrm{E} 4$, and A174D alleles. Hence, the probability that a HFI patient harbours these alleles is $\mathrm{p}^{2}$ for two alleles and 2pq for one allele, while the probability of 
Table 2 Genotypes and hepatic aldolase activities of HFI patients

\begin{tabular}{|c|c|c|c|c|c|}
\hline \multirow[b]{2}{*}{ Family } & \multirow[b]{2}{*}{ Proband } & \multirow[b]{2}{*}{ Genotype } & \multicolumn{3}{|c|}{ Aldolase activity (mU/mg protein) } \\
\hline & & & F-1-P & $\mathrm{F}-1,6-\mathrm{P}_{2}$ & $\begin{array}{l}\mathrm{F}-1-\mathrm{P} / \mathrm{F}-1,6-\mathrm{P}_{2} \\
\text { activity ratio }\end{array}$ \\
\hline \multirow[t]{2}{*}{$\mathrm{Fl}$} & $\mathrm{F} 1.3$ & $\mathrm{Al} 49 \mathrm{P} / \Delta 4 \mathrm{E} 4$ & ND & ND & ND \\
\hline & $\mathrm{F} 1.4$ & $\mathrm{Al} 49 \mathrm{P} / \Delta 4 \mathrm{E} 4$ & ND & ND & ND \\
\hline F2 & F2.3 & $\mathrm{A} 149 \mathrm{P} / \mathrm{A} 149 \mathrm{P}$ & 1.8 & 10.7 & 5.9 \\
\hline F3 & F3.4 & A149P/A174D & ND & ND & ND \\
\hline F5 & F5.3 & $\Delta 4 \mathrm{E} 4 / \Delta 4 \mathrm{E} 4$ & $<1.0$ & 6.8 & $>6.8$ \\
\hline F6 & F6.2 & A149P/A149P & 2.6 & 4.8 & 1.8 \\
\hline F7 & F7.4 & Al49P/Al49P & 2.7 & 9.4 & 3.5 \\
\hline \multirow[t]{2}{*}{ F8 } & F8.3 & A $149 P / \triangle 4 E 4$ & 1.4 & 5.4 & 3.6 \\
\hline & F8.4 & $\mathrm{A} 149 \mathrm{P} / \Delta 4 \mathrm{E} 4$ & ND & ND & ND \\
\hline \multirow[t]{2}{*}{ F11 } & $\mathrm{F} 11.3$ & $\mathrm{~A} 149 \mathrm{P} / \mathrm{g} \cdot \mathbf{4 2 7 1 \mathrm { C } > \mathrm { G }}$ & ND & ND & ND \\
\hline & F11.5 & $\mathrm{A} 149 \mathrm{P} / \mathrm{g} \cdot 4271 \mathrm{C}>\mathrm{G}$ & ND & ND & ND \\
\hline $\mathrm{F} 12$ & $\mathrm{~F} 12.3$ & Al49P/A149P & ND & ND & ND \\
\hline F13 & $\mathrm{F} 13.4$ & A149P/A149P & 2.5 & 8.4 & 3.3 \\
\hline \multirow[t]{2}{*}{ F16 } & $\mathrm{F} 16.3$ & $\mathrm{~A} 149 \mathrm{P} / \Delta 4 \mathrm{E} 4$ & ND & ND & ND \\
\hline & $\mathrm{F} 16.4$ & $\mathrm{~A} 149 \mathrm{P} / \Delta 4 \mathrm{E} 4$ & ND & ND & ND \\
\hline $\mathrm{F} 17$ & $\mathrm{~F} 17.3$ & A149P/A174D & 1.1 & 10.3 & 9.2 \\
\hline \multirow[t]{3}{*}{ F18 } & F18.1 & A $149 P / \triangle 4 E 4$ & ND & ND & ND \\
\hline & F18.3 & $\mathrm{A} 149 \mathrm{P} / \triangle 4 \mathrm{E} 4$ & 2.2 & 11.9 & 5.3 \\
\hline & F18.4 & Al49P/A149P & ND & ND & ND \\
\hline \multirow[t]{2}{*}{ F19 } & F19.1 & Al49P/A149P & ND & ND & ND \\
\hline & F19.4 & Al49P/A149P & $<1.0$ & 7.4 & $>7.4$ \\
\hline $71 F$ & 71 & $\mathrm{~A} 149 / \Delta 4 \mathrm{E} 4$ & $<1.0$ & 2.6 & $>2.6$ \\
\hline $210 F$ & 210 & A149P/A149P & 1.5 & 7.8 & 5.2 \\
\hline $468 \mathrm{~F}$ & 468 & $\mathrm{~A} 149 \mathrm{P} / \mathrm{N} 334 \mathrm{~K}$ & $<1.0$ & 12.2 & $>12.2$ \\
\hline $476 \mathrm{~F}$ & 476 & $\mathrm{~A} 174 \mathrm{D} / \mathrm{A} 174 \mathrm{D}$ & $<1.0$ & 10.2 & $>10.2$ \\
\hline $529 \mathrm{~F}$ & 529 & Al49P/g.1133G $>$ A & $<1.0$ & 1.8 & $>1.8$ \\
\hline $663 \mathrm{~F}$ & 663 & A149P/A149P & 3.0 & 7.3 & 2.4 \\
\hline $717 \mathrm{~F}$ & 717 & A149P/A149P & $<1.0$ & 5.5 & $>5.5$ \\
\hline \multicolumn{3}{|l|}{ Controls } & 24.0 (SD 8.4) & 22.4 (SD 8.0) & 1.1 (SD 0.3) \\
\hline \multicolumn{6}{|c|}{$\begin{array}{l}\text { The two aldolase B alleles in each subject are indicated. Novel alleles are in bold. Aldolase activity towards } \\
\text { fructose-1-phosphate (F-1-P) and fructose-1,6-bisphosphate }\left(\mathrm{F}-1,6-\mathrm{P}_{2}\right) \text { was assayed in hepatic biopsies, where } \\
\text { available, as indicated in Materials and methods. } \\
\text { ND, not determined. }\end{array}$} \\
\hline
\end{tabular}

having two mutant alleles other than Al49P, $\triangle 4 \mathrm{E} 4$, or Al74D is $\mathrm{q}^{2}$ (where $\mathrm{q}=1-\mathrm{p}$ ).

\section{RESULTS}

\section{Screening for common ALDOB gene mutations in HFI patients}

We investigated the presence of mutations in the $A L D O B$ gene associated with HFI in Spanish patients. First, a molecular analysis to search for the three major mutations in European HFI populations, Al49P, Al74D, and N334K, ${ }^{34}$ was performed using restriction digestion or ASO hybridisation. Fig 1A, B, and $\mathrm{C}$ shows examples of the detection of these mutant alleles in several HFI families. As a result of this screening, 11 patients were found to be Al49P homozygotes and another 15 patients carried a single copy of the Al49P allele. Among the latter, there were two Al49P/Al74D and one Al49P/N334K compound heterozygotes. Another patient was found to be homozygous for the A174D mutation. The individual aldolase B genotypes of all patients studied is shown in table 2 .

The presence of another widespread HFI allele, $\Delta 4 \mathrm{E} 4$, was then analysed by DNA sequencing and ASO hybridisation (fig 1D). This allele was found in patients from six families; one patient was found to be a $\Delta 4 \mathrm{E} 4$ homozygote and nine were Al49P/D4E4 compound heterozygotes (table 2).

In four patients $(210,476,663$, and 717$)$ who appeared to be homozygous for either the Al49P or the Al74D mutations (table 2), the mutant aldolase B alleles could not be traced back because samples from their parents were not available. To test the presence of large deletions or rearrangements in aldolase B alleles, genomic DNA from these patients and from an unaffected control was subjected to Southern blot analysis. Thus, EcoRI digested genomic DNA was hybridised to an aldo- lase B cDNA probe; in all cases, only the two expected bands of sizes about 5.8 and $8.5 \mathrm{~kb}^{220}$ were detected (not shown).

\section{Screening for other ALDOB gene mutations in HFI patients}

Further screening of less common or unknown HFI alleles by direct sequencing of PCR products corresponding to the coding exons plus intron-exon boundaries of the $A L D O B$ gene led us to the identification of two novel sequence variations associated with HFI, designated g.4271C $>$ G and g.1133G $>$ A following the recommendations for mutation nomenclature compiled by Antonarakis et al. ${ }^{21} 22$ The g.427lC $>\mathrm{G}$ mutation is a $\mathrm{C} \rightarrow \mathrm{G}$ transversion of the second base of codon 184 in exon 6 , which is inferred to replace the normal proline with an arginine residue in the aldolase B protein. Thus, we propose P184R as a trivial name for this sequence variation. The mutation was found by direct sequencing of exon 6 in DNA from two subjects from a single family (not shown), who were suspected of having HFI on the basis of dietary intolerance and clinical evaluation. The g.4271C $>\mathrm{G}$ mutation eliminates a BanI restriction site (GGTACC), which allowed mutation detection by restriction analysis to follow the segregation of the mutant allele in the probands' family (fig 2). The two HFI patients (F11.3 and F11.5) were Al49P/g.4271C $>$ G compound heterozygotes (table 2).

The g.1133G $>$ A mutation was found by direct sequencing of aldolase B exons (fig 3), in a single allele of an HFI patient, named 529, whose hepatic aldolase B deficiency was shown by enzymatic assays. The other HFI allele in this subject was Al49P (table 2); no other $A L D O B$ gene abnormalities could be found by either direct sequencing of aldolase $\mathrm{B}$ exons or Southern blotting (not shown). The g.1133G $>$ A mutation is a 


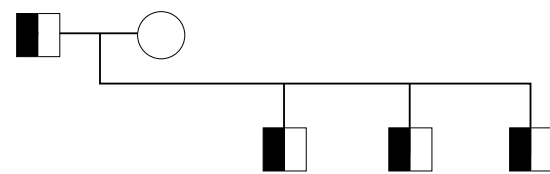

$\begin{array}{lllll}\text { F11.1 F11.2 F11.3 F11.4 F11.5 } & \end{array}$

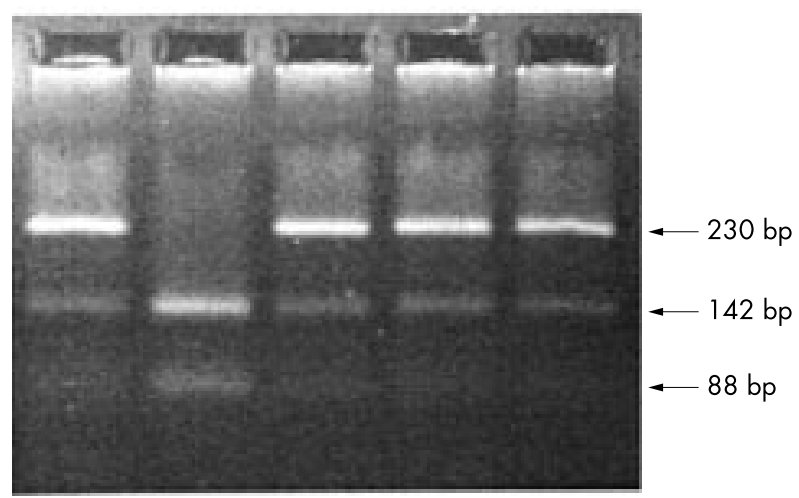

Figure 2 Segregation of the g.4271C>G mutation in family F1 1 . A PCR fragment corresponding to exon 6 of aldolase $B$ was digested with Banl as indicated in Materials and methods. Arrows indicate the position of diagnostic bands of 230, 142, and $88 \mathrm{bp}$. F11.1

$\mathrm{F} 11.3, \mathrm{~F} 11.4$, and F11.5 were heterozygous for the $\mathrm{g} .4271 \mathrm{C}>\mathrm{G}$ allele; F1 1.2, wild type homozygote.

single $\mathrm{G}$ to A transition in the last nucleotide of exon 3, which is silent with respect to the amino acid encoded, Lys 324. However, since the changed nucleotide was located at the -1 position of the 5' splice site of intron 3 of the $A L D O B$ gene, and similar variations of nucleotides surrounding splice sites in other genes can indeed provoke changes in mRNA splicing, ${ }^{23}{ }^{24}$ we decided to investigate whether the g.1133G $>$ A mutation could alter mRNA processing. We obtained total cDNA by reverse transcription of total RNA isolated from hepatic biopsy samples from the patient and from an unaffected control. Then, we amplified aldolase B cDNA by PCR with total CDNA as template, and fragments corresponding to nucleotides -37 to 1173 of aldolase B cDNA were subcloned in pBluescript. The resulting constructs were sequenced with different primers covering the complete cDNA insert sequence. Among 10 plasmids containing cDNA from patient 529, six had a normal aldolase B cDNA sequence except for the presence of a $\mathrm{G} \rightarrow \mathrm{C}$ transversion corresponding to the Al49P mutation (not shown), previously detected at the genomic level in one of the patient's aldolase $\mathrm{B}$ alleles. Thus, these plasmids (named pAl49P) contained aldolase B cDNA sequence derived from the expression of the Al49P allele. In the other four plasmids, named pAl49WT, we found a normal DNA sequence at codon 149 (not shown), and therefore they contained aldolase B cDNA derived from the non-Al49P allele. However, all these pA149WT plasmids bore a deletion of the last 12 nucleotides of exon 3 (fig 4A). This result suggested that the g.1133G $>$ A mutation could cause a splicing defect resulting in the elimination of nucleotides 1122 to 1133 of the $A L D O B$ gene from its mRNA. It is hypothesised that the g.1133G $>$ A mutation could impair recognition of the normal $5^{\prime}$ splice site of intron 3 by the splicing machinery so that a cryptic site located 12 nucleotides upstream would be activated (fig 4B). The nucleotide deletion at the mRNA level is deduced to eliminate four amino acid residues (104-107) from the aldolase B protein, keeping the rest of the message in frame.

In order to characterise better the effects of the g.1133G $>A$ mutation on aldolase $\mathrm{B}$ cDNA, fragments corresponding to nucleotides 250 to 553 of aldolase B cDNA (E3-6 fragments), containing part of exon 3, exons 4 and 5, and part of exon 6 sequences, were amplified from either total liver cDNA or from pAl49P or pAl49WT plasmids, and resolved by nondenaturing polyacrylamide gel electrophoresis. PCR from total cDNA from patient 529 yielded two products which migrated as separate bands under polyacrylamide gel electrophoresis (not shown). The upper band corresponded to the full length, $304 \mathrm{bp}$ fragment, which was also the only band observed when amplification was carried out with either total cDNA from a control subject or pAl49P DNA as templates. The lower band corresponded to the deleted form of aldolase B cDNA E3-6 fragments, $292 \mathrm{bp}$ in length, which was the only PCR product obtained by amplification from pAl49WT. We analysed 39 independent plasmids containing aldolase B cDNA from patient 529 of which 14 corresponded to the pAl49WT type as determined by BsaHI digestion. ${ }^{9}$ Amplification of E3-6 fragments by PCR from pAl49WT plasmids only yielded the shorter, 12 nucleotide deleted form of the aldolase B cDNA fragment (not shown).

Finally, we performed the amplification of E3-6 fragments from total cDNA from patient 529 in the presence of $\left[\alpha{ }^{32} \mathrm{P}\right] \mathrm{dCTP}$, in an attempt to estimate the relative amounts of the two aldolase B cDNA fragments. As shown in fig 5, radioactivity incorporation into the two PCR products was exponential for 19 to 24 cycles; the efficiency factor (R) calculated as indicated by Chelly $e t a^{25}$ was 0.70 and 0.72 for amplification of the 292 and 304 bp fragments, respectively. However, the radioactivity incorporated into the $292 \mathrm{bp}$ fragment appeared to be reduced by $36-44 \%$ in comparison to that determined for the $304 \mathrm{bp}$ fragment (fig 5B), thus indicating that there was a reduced amount of the 12 nucleotide deleted fragment.

\section{Aldolase activity in samples from HFI patients}

We also measured aldolase activity in hepatic biopsies from HFI patients where they were available for diagnosis by enzymatic assays. As previously established, ${ }^{1}$ in all HFI samples analysed, aldolase activities against fructose-1-phosphate were lower than $15 \%$ of the mean activities in control biopsies, and the ratios between aldolase activities against fructose-1phosphate and fructose-1,6-bisphosphate were higher than 1.7 in patients, while those of control subjects were 1.1 (SD 0.3 ) (table 2). However, both the specific activities against fructose-1-phosphate and the ratios of activity against the two aldolase substrates varied broadly within a single genotype (for example, among Al49P homozygotes). Hence, these

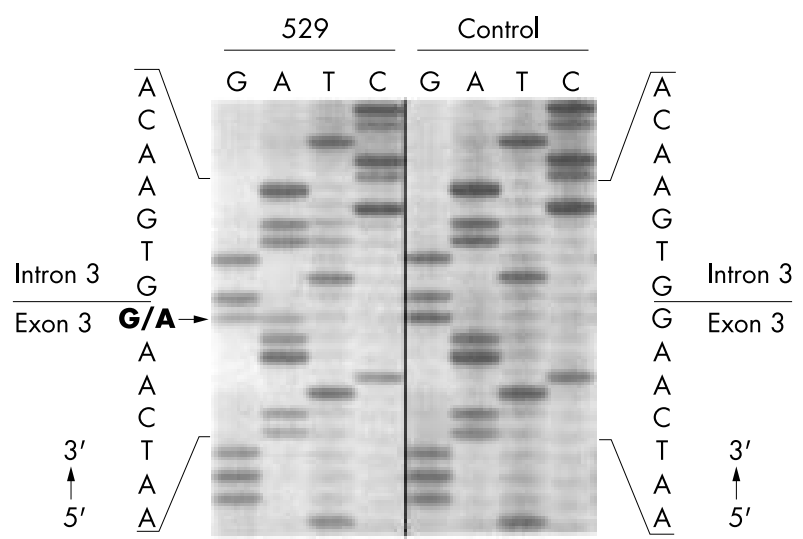

Figure 3 Sequence of the exon $3 /$ intron 3 region of the $A L D O B$ gene in patient 529. A DNA fragment corresponding to exon 3 of aldolase $B$ was generated by PCR from genomic DNA obtained from patient 529 and sequenced as indicated in Materials and methods. Partial sequences of DNA from patient 529 and a healthy control, including the exon 3 /intron 3 boundaries, are shown. The arrow indicates the position of the g.1133G>A mutation in the patient's DNA. 
A

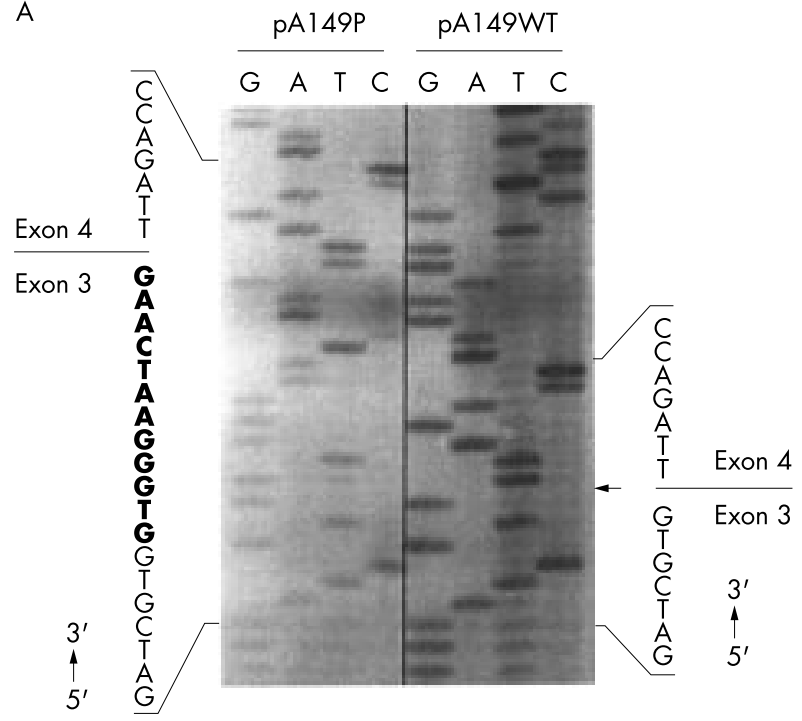

B

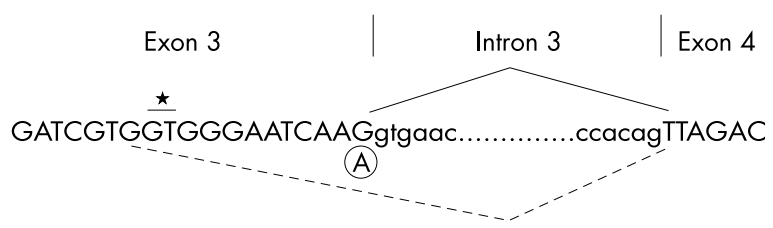

Figure 4 Sequence of the exon 3/exon 4 region of the aldolase $B$ cDNA in patient 529. DNA fragments corresponding to nucleotides -37 to 1173 of human aldolase B cDNA, obtained by RT-PCR, were subcloned in pBluescript II and the resulting plasmid constructs were sequenced. (A) Partial DNA sequences around the exon 3/exon 4 boundaries of two representative constructs, pA 149P and pA149WT (see text). The arrow indicates the site of the 12 nucleotide deletion in pA149WT. (B) Schematic representation of the possible splicing patterns of the $A L D O B$ gene in patient 529. The upper line and the lower, discontinuous line represent the normal and aberrant splicing patterns, respectively. Capital letters indicate exonic sequences, while intron sequences are expressed in lower case letters. The GT dinucleotide of the putative splice site activated in the presence of the g. $1133 \mathrm{G}>\mathrm{A}$ mutation is indicated by an asterisk.

results did not allow us to establish a correlation between genotypes and residual aldolase B activities.

\section{Mutation frequencies}

The distribution of allele frequencies among the independent families studied is shown in table 3. The prevalent Al49P mutation was present in 29 of 43 independent HFI alleles (one family had three probands with three independently segregating alleles), thus giving a frequency of $67.4 \%$, which was very similar to those reported in pan-European populations, ${ }^{11}{ }^{14}$ but higher than that reported (29\%) in HFI patients from Italy. ${ }^{26}$ The frequency of the $\Delta 4 \mathrm{E} 4$ mutation, $16.3 \%$, was much higher than its world wide frequency as reported by Tolan, ${ }^{3}$ but quite similar to that found in Italy (18.5\%). ${ }^{26}$ The A174D and N334K mutations had frequencies somewhat lower than those reported in either pan-European or world wide population studies. ${ }^{311} 14$

Regarding the distribution of HFI alleles and genotypes found in this study, it is worth noting that all the HFI patients analysed had at least one A149P, $\Delta 4 \mathrm{E} 4$, or A174D allele (table 2 ). Assuming a binomial distribution for these common alleles, it can be estimated that $93.0 \pm 7.6 \%$ (95\% confidence limits) of the independent HFI alleles would be accounted for by Al49P, $\triangle 4 \mathrm{E} 4$, and A174D. At the lower limit, therefore, $97.8 \%$ of HFI patients $\left(0.854^{2}+(2 \times 0.854 \times 0.146)\right)$ would be
A
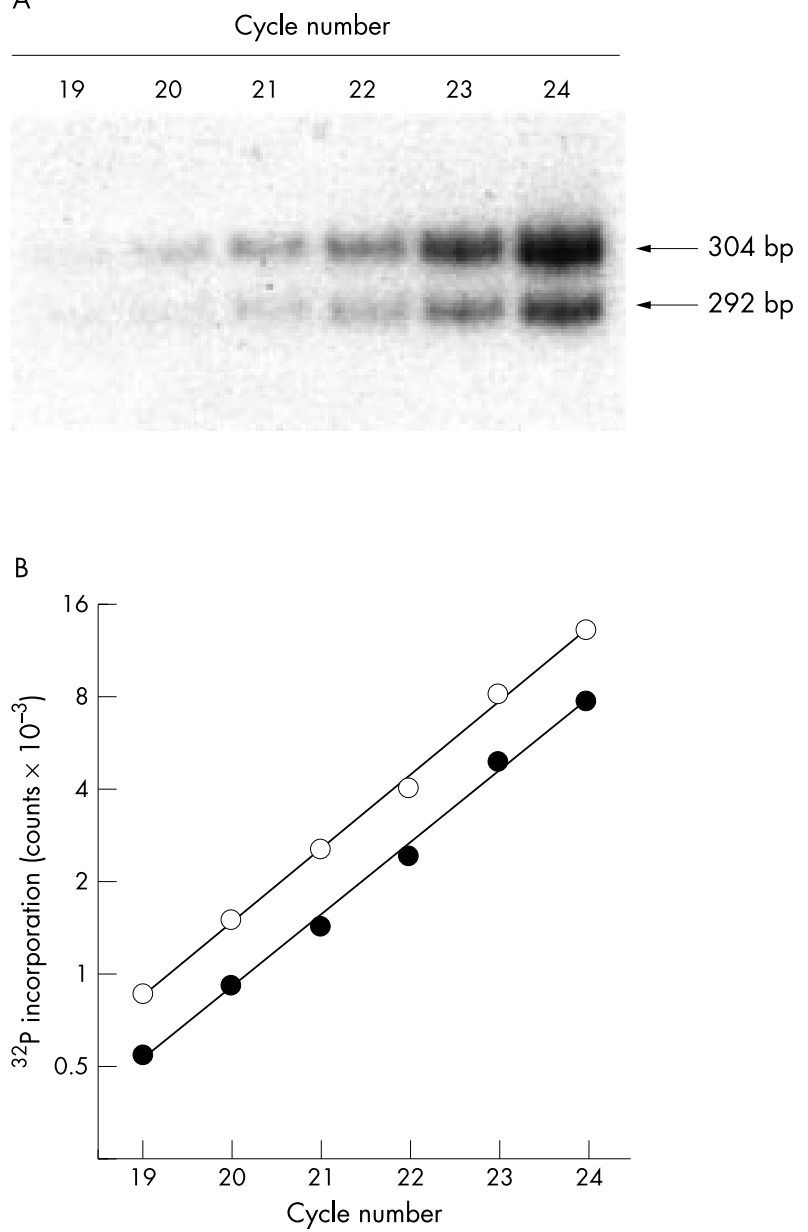

Figure 5 Amplification of E3-6 aldolase B cDNA fragments from patient 529. DNA fragments corresponding to nucleotides 250 to 553 of human aldolase $B$ CDNA (E3-6 fragments) were amplified by PCR in the presence of $10 \mu \mathrm{Ci}\left[\alpha-{ }^{32} \mathrm{P}\right] \mathrm{dCTP}$ and at the indicated cycle numbers aliquots of the PCR mixture (1/10 of initial volume) were taken, pipetted into a fresh tube, and kept at $-20^{\circ} \mathrm{C}$ until electrophoresis on $6 \%$ polyacrylamide was performed. (A) Visualisation of the PCR products after electrophoresis and autoradiography. Arrows indicate the positions of the bands of 304 and $292 \mathrm{bp}$. (B) Quantitative analysis of ${ }^{32} \mathrm{P}$ incorporation into PCR products of 304 (open circles) or $292 \mathrm{bp}$ (solid circles). The gel corresponding to the autoradiograph in $(A)$ was exposed for radioactivity counting in an Instantlmager apparatus.

expected to carry at least one of these three alleles, and only $2.2 \%$ would carry two mutant alleles different from Al49P, $\Delta 4 \mathrm{E} 4$, or A174D. These estimations are close to the results of this survey, in which the actual frequency of HFI patients carrying at least one copy of these three alleles reached 100\%.

\section{DISCUSSION}

The aim of this work was to investigate the mutations in the $A L D O B$ gene associated with HFI in a population sample of 28 patients from 21 independent families, referred by several hospitals in Spain. With the aid of PCR amplification of aldolase $\mathrm{B}$ exons and conventional molecular biology techniques, we have identified the HFI mutations present in all patients. Four mutations (Al49P, A174D, $44 \mathrm{E} 4$, and N334K) have been previously described in other studies and are considered widespread, relatively frequent mutations. ${ }^{34}$ In addition, we have found two novel HFI alleles, termed g.4271C $>\mathrm{G}$ and g.1133G $>$ A, each present in one gene copy in patients from different families. 
Table 3 Allele frequencies in 21 independent Spanish HFI families

\begin{tabular}{llll}
\hline Mutation & No of alleles & Frequency (\%) & $\begin{array}{l}\text { Reported } \\
\text { frequency (\%) }\end{array}$ \\
\hline A149P & 29 & 67.4 & $61.0^{*}$ \\
$\Delta 4 \mathrm{E} 4$ & 7 & 16.3 & $1.8 \dagger$ \\
A174D & 4 & 9.3 & $15.8^{*}$ \\
N334K & 1 & 2.3 & $7.2^{*}$ \\
g. $1133 G>A$ & 1 & 2.3 & - \\
g.4271C $>$ G & 1 & 2.3 & - \\
Total & 43 & 100 & \\
\hline
\end{tabular}

The number of independently segregating HFI alleles and their frequencies are indicated. One family had three probands with three independent mutant alleles. Reported frequencies are those described by ${ }^{*}$ Cox in a pan-European population sample" or TTolan in a compendium of studies world wide. ${ }^{3}$

The g.4271C $>\mathrm{G}$ mutation changes the sequence at codon 184 from CCT to CGT, and therefore is deduced to replace a proline residue with an arginine at position 184 of the aldolase B protein. This would be a non-conservative substitution of a residue which is conserved in eukaryotic aldolases ${ }^{27}$ and located in the vicinity of other conserved residues involved in active site formation, such as Ile-185, Glu-187, and Glu-189. ${ }^{28}$ These facts strongly support that the g.427lC $>$ G mutation can cause aldolase B deficiency. However, in the absence of hepatic aldolase activity determinations in the affected patients, assessment of the effects caused by the g.4271C $>$ G mutation on enzyme activity would require further studies.

The g.1133G > A mutation is a single $\mathrm{G}$ to A transition in the last nucleotide of exon 3, which does not change the sense of the affected codon. Nevertheless, the changed nucleotide is located at the -1 position of the $5^{\prime}$ splice site of intron 3 of the $A L D O B$ gene. At least 10 identical nucleotide changes have been shown to cause abnormal RNA splicing in different mammalian genes. ${ }^{23}{ }^{24}$ In addition, many of these sequence variations have been associated with hereditary human diseases. $^{29-31}$ In agreement with this, we found that the g.1133G $>$ A mutation provoked a deletion of the last 12 nucleotides of exon 3 from aldolase B cDNA. A reasonable explanation for this deletion is that the point mutation at the splice site would allow the use of an alternative, cryptic $5^{\prime}$ splice site located 12 nucleotides upstream from the normal site by the splicing machinery; actually, a GT sequence is located in the $A L D O B$ gene just at the $5^{\prime}$ end of the deleted sequence, and is preceded by a $\mathrm{G}$ at the -1 position as is the GT invariant dinucleotide in the normal $5^{\prime}$ splice site of intron 3. This hypothesis is in agreement with the concept that most cryptic sites activated by mutations in splice sites are located within 100 nucleotides from the authentic site. ${ }^{24}$ In addition, we were not able to detect any aldolase B cDNA fragment of normal length derived from the g.1133G $>$ A allele, which suggests that missplicing is present in at least a large majority of mRNA molecules transcribed from this aldolase B allele in the liver sample from the patient. The mutated aldolase $\mathrm{B}$ mRNA originating from the g.1133G $>$ A allele should be translated into a protein in which four amino acids (residues 104-107) have been eliminated, while the remainder of the protein sequence is kept intact. This modification at the protein level could alter the stability and/or the catalytic properties of the enzyme and thus contribute to the HFI phenotype, but further studies are needed to test this possibility.

By assaying the incorporation of radioactivity from $\left[\alpha-{ }^{32} \mathrm{P}\right] \mathrm{dCTP}$ into aldolase B cDNA products amplified from patient's total cDNA, we observed an apparent reduction of around $40 \%$ in the quantity of the 12 nucleotide deleted cDNA fragment, in comparison with that of the normal length fragment. This finding suggests that the g.1133G $>$ A mutation could provoke a reduction in the levels of mature aldolase $\mathrm{B}$ mRNA. In connection with this, a $\mathrm{G}$ to A mutation at position -1 of the $5^{\prime}$ splice site of intron 5 of the gene encoding $\beta$-hexosaminidase $\alpha$ subunit causes both the skipping of the mutated exon and a $90 \%$ reduction in the levels of $\beta$-hexosaminidase $\alpha$ mRNA. ${ }^{30}$ Furthermore, mutations in the $\beta$-globin gene that reduce the efficiency of pre-mRNA splicing cause the degradation and/or retention of unprocessed transcripts in the nucleus. ${ }^{32}{ }^{33}$ Thus, it is conceivable that the g.1133G $>$ A mutation, besides promoting the use of a cryptic splice site, may impair the efficiency of splicing of mRNA precursors and therefore give rise to deficiently processed transcripts that are degraded in the nucleus.

In addition to the genetic analysis, aldolase activity assays were performed in a number of liver samples from HFI patients. They confirmed aldolase B deficiency in all cases assayed regardless of individual genotypes. However, we could not find a close relationship between mutated aldolase B alleles and residual enzyme activities in hepatic biopsies; this was because of considerable variability in both specific aldolase $\mathrm{B}$ activities and aldolase activity ratios among patients with the same HFI genotypes and because for most of these genotypes there was a single biopsy determination.

The present work is the first study of the genetics of HFI in a population sample of Spanish patients. The allele frequencies found have been compared with those previously reported in different populations. In our study, the A149P allele showed the highest frequency, which was quite similar to those reported in pan-European studies, supporting the concept that this mutation arose early during the evolution of modern populations. ${ }^{4}$ The A174D and N334K mutations, which are relatively common in European HFI patients, ${ }^{11}{ }^{14}$ reached low frequencies in our patient population. These results are in agreement with the geographical distribution of HFI mutations proposed by several authors, ${ }^{3}$ who suggest that the A149P mutation is widely distributed among European populations, while the N334K allele occurs mainly in central and eastern Europe, and the A174D allele in central and southern European locations. The relatively high incidence of the $\Delta 4 \mathrm{E} 4$ mutation ( $16 \%$ of HFI alleles) is noteworthy, comparable to that observed in Italian HFI patients. ${ }^{26}$ Thus, it appears that this allele is more abundant in southern Europe. It is worth mentioning that the P184R mutation, reported here for the first time, was found in a Spanish family from the Spanish territories in North Africa. Thus, P184R may represent a geographically restricted ("private") mutation ${ }^{4}$ and/or a relatively frequent HFI allele in populations from North Africa, but further data are needed to support this speculation.

The distribution of HFI alleles among the patients studied in this work indicates that $93.0 \pm 7.6 \%$ of independent alleles would be accounted for by Al49P, $\triangle 4 \mathrm{E} 4$, and Al74D, assuming that the presence of these alleles in HFI patients follows a binomial distribution. Moreover, at the lower confidence limit, $97.8 \%$ of the patients would be expected to carry at least one copy of these three alleles. Therefore, analysis of the presence of these mutations in Spanish subjects suspected of having HFI could be of considerable diagnostic relevance. In this sense, some authors have adopted a protocol for the genetic diagnosis of $\mathrm{HFI}^{4}$ that, in view of our results, could be applied with some modifications for genetic diagnosis of HFI in Spain. Thus, an initial screening for the presence of A149P, A174D, $\triangle 4 \mathrm{E} 4$, and $\mathrm{N} 334 \mathrm{~K}$ mutations by restriction endonuclease digestion and ASO hybridisation would be carried out; identification of any of these mutant alleles in at least a single copy in a symptomatic patient would be indicative of HFI. Then, if the other allele were different, direct sequencing of aldolase B exons and exon/intron boundaries would be performed to identify the second allele and confirm HFI diagnosis. Subjects not having any of the four common mutant alleles, and if their parents were not related, would be studied further only if a positive clinical or enzymatic test had been obtained 
previously. In the event of consanguinity between the proband's parents, then clinical symptoms should indicate the need to perform a search for the mutant aldolase B allele(s) by direct sequencing. It must be stressed that, in contrast to other tests applied for confirmation of HFI diagnosis, genetic analysis allows for both confirmatory diagnosis and genetic counselling with little discomfort to the probands, since it only requires a small sample of peripheral blood.

\section{ACKNOWLEDGEMENTS}

This work was supported by "Fondo de Investigación Sanitaria" (grants No 96/2030 and 01/0225), Spanish Ministry of Health. JCS-G is funded by the programme "Contratos de Investigadores en el Sistema Nacional de Salud", FIS, Spanish Ministry of Health. Critical reading of the manuscript by $\mathrm{J} G$ Castaño and R Garesse is gratefully acknowledged.

\section{Authors' affiliations}

J C Sánchez-Gutiérrez, T Benlloch, M A Leal, B Samper, I

García-Ripoll, J E Felíu, Servicio de Endocrinología Experimental, Hospital Universitario Clínica Puerta de Hierro and Departamento de Bioquímica, Facultad de Medicina, Universidad Autónoma de Madrid, Madrid, Spain

Correspondence to: Dr J C Sánchez-Gutiérrez, Servicio de Endocrinología Experimental, Hospital Universitario Clínica Puerta de Hierro, San Martín de Porres 4, 28035 Madrid, Spain; juliocesar.sanchez@uam.es

\section{REFERENCES}

1 Gitzelmann R, Steinmann B, Van den Berghe G. Disorders of fructose metabolism. In: Scriver CR, Beaudet AL, Sly WS, Valle D, eds. The metabolic and molecular bases of inherited disease. 7th ed. New York: McGraw-Hill, 1994:905-34.

2 Tolan DR, Penhoet EE. Characterisation of the human aldolase $B$ gene. Mol Biol Med 1986:3:245-64

3 Tolan DR. Molecular basis of hereditary fructose intolerance: mutations and polymorphisms in the human aldolase B gene. Hum Mutat 1995;6:210-18

4 Ali M, Rellos P, Cox TM. Hereditary fructose intolerance. J Med Genet 1998;35:353-65

5 Santamaria R, Vitagliano L, Tamasi S, Izzo P, Zancan L, Zagari A, Salvatore F. Novel six-nucleotide deletion in the hepatic fructose-1,6-bisphosphate aldolase gene in a patient with hereditary fructose intolerance and enzyme structure-function implications. Eur J Hum Genet 1999:7:409-14.

6 Rellos P, Ali M, Vidailhet M, Sygusch J, Cox TM. Alteration of substrate specificity by a naturally-occurring aldolase $B$ mutation $\left(\mathrm{Ala}^{337} \rightarrow \mathrm{Val}\right)$ in fructose intolerance. Biochem J 1999;340:321-7.

7 Rellos P, Sygusch J, Cox TM. Expression, purification, and characterization of natural mutants of human aldolase $B$. Role of quaternary structure in catalysis. J Biol Chem 2000;275: $1145-51$

8 Santamaria R, Esposito G, Vitagliano L, Race V, Paglionico I, Zancan L, Zagari A, Salvatore F. Functional and molecular modelling studies of two hereditary fructose intolerance-causing mutations at arginine 303 in human liver aldolase. Biochem J 2000;350:823-8.

9 Cross NCP, Tolan DR, Cox TM. Catalytic deficiency of human aldolase $b$ in hereditary fructose intolerance caused by a common missense mutation. Cell 1988;53:881-5.

10 James CL, Rellos P, Ali M, Heeley AF, Cox TM. Neonatal screening for hereditary fructose intolerance: frequency of the most common mutant aldolase B allele (A149P) in the British population. J Med Genet 1996;33:837-41
11 Cox TM. Aldolase B and fructose intolerance. FASEB J 1994:8:62-71.

12 Sambrook J, Fritsch EF, Maniatis T. Molecular cloning: a laboratory manual. 2nd ed. New York: Cold Spring Harbor Laboratory Press 1989.

13 Laird PW, Zijderveld A, Linders K, Rudnicki MA, Jaenicsh R, Berns A. Simplified mammalian DNA isolation procedure. Nucleic Acids Res 1991; 19:4293

14 Cross NCP, de Franchis R, Sebastio G, Dazzo C, Tolan DR, Gregori C, Odievre M, Vidailhet M, Romano V, Mascali G, Romano C, Musumeci S, Steinman B, Gitzelmann R, Cox TM. Molecular analysis of aldolase B genes in hereditary fructose intolerance. Lancet 1990;335:306-9.

15 Dazzo C, Tolan DR. Molecular evidence for compound heterozygosity in hereditary fructose intolerance. Am J Hum Genet 1990;46:1 194-9.

16 Chomczynski P, Sacchi N. Single-step method of RNA isolation by acid guanidinium thiocyanate-phenol-chloroform extraction. Anal Biochem 1987; 162:156-9.

17 Rottman WH, Tolan DR, Penhoet EE. Complete amino acid sequence for human aldolase B derived from cDNA and genomic clones. Proc Natl Acad Sci USA 1984;81:2738-42.

18 Blostein R, Rutter WJ. Comparative studies of liver and muscle aldolase. II. Immunochemical and chromatographic differentiation. J Biol Chem 1963;238:3280-5.

19 Lowry OH, Rosebrough NJ, Farr AL, Randall RR. Protein measurement with the folin phenol reagent. J Biol Chem 1951;193:265-75

20 Cross NCP, Cox TM. Partial aldolase B gene deletions in hereditary fructose intolerance. Am J Hum Genet 1990;47:101-6.

21 Antonarakis SE, Nomenclature Working Group. Recommendations for a nomenclature system for human gene mutations. Hum Mutat 1998; 11:1-3.

22 den Dunnen JT, Antonarakis SE. Mutation nomenclature extensions and suggestions to describe complex mutations: a discussion. Hum Muta 2000;15:7-12.

23 Krawczak M, Reiss J, Cooper DN. The mutational spectrum of single base-pair substitutions in mRNA splice junctions of human genes: causes and consequences. Hum Genet 1992;90:41-54

24 Nakai K, Sakamoto H. Construction of a novel database containing aberrant splicing mutations of mammalian genes. Gene 1994;141:171-7. (The mutation database described is available at the following internet address: http://www.hgc.ims.u-tokyo.ac.jp/ knakai/ asdb.html).

25 Chelly J, Kaplan JC, Maire P, Gautron S, Kahn A. Transcription of the dystrophin gene in human muscle and non-muscle tissues. Nature 1988;333:858-60.

26 Santamaria R, Tamasi S, Del Piano G, Sebastio G, Andria G, Borrone C, Faldella G, Izzo P, Salvatore F. Molecular basis of hereditary fructose intolerance in Italy: identification of two novel mutations in the aldolase $B$ gene. J Med Genet 1996;33:786-8.

27 Berardini T, Amsden AB, Penhoet EE, Tolan DR. Identification of conserved promoter elements for aldB and isozyme specific residues in aldolase B. Comp Biochem Physiol B 1999;122:53-61.

28 Sygusch J, Beaudry D, Allaire M. Molecular achitectures of rabbit skeletal muscle aldolase at 2.7-Å resolution. Proc Natl Acad Sci USA 1987:84:7846-50.

29 Weil D, D'Alessio M, Ramirez F, Steinmann B, Wirtz MK, Glanville RW Hollister DW. Temperature-dependent expression of a collagen splicing defect in the fibroblasts of a patient with Ehlers-Danlos syndrome type VII J Biol Chem 1989;264:16804-9.

30 Akli S, Chelly J, Mezard C, Gandy S, Kahn A, Poenaru L. A "G" to "A" mutation at position -1 of a $5^{\prime}$ splice site in a late infantile form of Tay-Sachs disease. J Biol Chem 1990;265:7324-30.

31 Herring WJ, McKean M, Dracopoli N, Danner DJ. Branched chain acyltransferase absence due to an Alu-based genomic deletion allele and an exon skipping allele in a compound heterozygote proband expressing maple syrup urine disease. Biochim Biophys Acta 1992;1138:236-42.

32 Treisman R, Orkin SH, Maniatis T. Specific transcription and RNA splicing defects in five cloned $\beta$-thalassaemia genes. Nature 1983;302:591-6.

33 Antoniou M, Geraghty F, Hurst J, Grosveld F. Efficient 3'-end formation of human $\beta$-globin mRNA in vivo requires sequences within the last intron but occurs independently of the splicing reaction. Nucleic Acids Res 1998;26:721-9. 